\title{
1103 Paulsen anacı üzerine aşılanan bazı sofralık üzüm çeşitlerinin açık köklü fidan randımanlarının belirlenmesi
}

\section{Determination of open rooted seedlings yield of some table grape varieties grafted onto 1103 Paulsen rootstock}

\author{
Tuba UZUN ${ }^{1 *}$ iD \\ ${ }^{1}$ Siirt Üniversitesi, Ziraat Fakültesi, Bahçe Bitkileri Bölümü, 56000, Siirt/Türkiye
}

\section{To cite this article:}

Uzun, T. (2019). 1103 Paulsen anacı üzerine aşılanan bazı sofralık üzüm çeşitlerinin açık köklü fidan randımanlarının belirlenmesi. Harran Tarım ve Gıda Bilimleri Dergisi, 23(3): 287-264.

DOI: 10.29050/harranziraat.519421

Address for Correspondence: Tuba UZUN

e-mail:

tubauzun@siirt.edu.tr

\section{Received Date:}

30.01.2019

Accepted Date:

09.05.2019

(C) Copyright 2018 by Harran University Faculty of Agriculture. Available on-line at www.dergipark.gov.tr/harranziraat

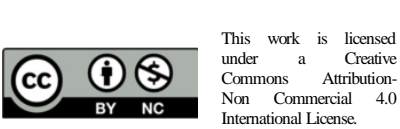

\section{öz}

Bu çalışma, Tokat Merkez ilçede bulunan "Kazova Vasfi Diren Tarım İşletmesi”nin bağ fidanı üretim tesisinde yürütülmüştür. Denemede, 1103 Paulsen Amerikan asma anacı üzerine aşılanan sekiz sofralık üzüm çeşidi (Cardinal, Ata Sarısı, Uslu, Trakya IIlkeren, Alphonse Lavallèe, Hamburg Misketi, Çavuş, Yalova İncisi)'nin fidan randımanı belirlenmiştir. En yüksek fidan randımanı, Trakya ilkeren çeşidinde (\% 98.53) belirlenirken; en düşük fidan randımanı, Hamburg Misketi çeşidinde (\% 67.53) tespit edilmiştir.

Anahtar Kelimeler: Amerikan asma anacı, Aşılı asma fidanı, Omega aşıSı, Fidan randımanı

\section{ABSTRACT}

This study was carried out in the vine sapling production unit of "Kazova Vasfi Diren Agricultural Administration" located Tokat Central district. In the experiment, was determined sapling yield of eigth table grape varieties (Cardinal, Ata Sarısı, Uslu, Trakya Illkeren, Alphonse Lavallèe, Hamburg Misketi, Çavuş, Yalova İncisi) grafted on 1103 Paulsen rootstock. While the highest sapling yield was determined in Trakya Illkeren variety (98.53\%); the lowest sapling yield was determined in the Hamburg Misketi variety (67.53\%).

Key Words: American vine rootstock, Grafted grapevine sapling, Omega grafting, Sapling yield

\section{Giriş}

Ülkemiz bağ alanlarının büyük bir kısmının filoksera (Viteus vitifolii Fitch.) zararlısıyla bulaşık olması nedeniyle (illter ve ark., 1984), çoğu üzüm çeşidi kaybolma tehlikesiyle karşı karşıya kalmıştır (Yayla, 2008). Asma köklerinden beslenen filoksera zararlısı 1863 yılında, Fransa'dan başlayarak tüm Avrupa ve Türkiye bağlarına yayılmıştır. Toprağın ilaçlanması, bağların su altında bırakılması ve karantina tedbirleri gibi önlemler filokseranın zarar verdiği bağların yeniden kurtarılması için denenmiş, ancak olumlu bir sonuç alınamamıştır. 1869 yılında Fransız bağcı Laliman yapmış olduğu araştırmalarda, bazı Amerikan asma anaçlarının filokseraya mukavemetinin yüksek olduğunu görmüş, kültür çeşitlerini bu anaçlar üzerine aşılamış ve başarılı sonuçlar almıştır (Winkler ve ark., 1974). Bu nedenle kârlı bir üzüm yetiştiriciliği için, bu zararlıya dayanıklı olan Amerikan asma anaçlarının kullanımı zorunludur (Çelik ve ark., 1998; Çelik, 2007). Kaliteli üzüm üretimi amacıyla planlanan tesislerde, modern bağcılığın temel koşulu, ismine doğru, fidan üretim materyali ile taşınan virüs ve virüs benzeri hastalık ve 
zararlılardan arî, sağlıklı ve kaliteli, yani sertifikalı asma fidanlarının kullanımıdır. Sertifikalı fidan üretim ve denetim sistemlerinin oluşturulması aşamalarının bütünü olan fidan sertifikasyonu, ülkemizde çözüm bekleyen bir sorundur (Söylemezoğlu ve ark., 2010).

Aşıda başarı denildiğinde, iki bitki parçasının birleşme noktasında öncelikle anaçtaki kambiyumdan meydana gelen ve parankimatik doku yığını halinde olan yara dokusunun (kallus) farklılaşarak iki bitki parçası arasındaki iletim demetlerinin birleşmesinin sağlaması anlaşılmaktadır (Janick, 1986). Anaçların, üzerine aşılandıkları çeşitle olan afinitesi sadece fidan randımanını değil, çeşidin bağda göstereceği verim ve kalite düzeyini de etkilemektedir (Kısmalı, 1978). Fidanlık şartlarında yapılan üretimde, kayıpların en aza indirilmesi ve üstün nitelikli fidan elde edilebilmesi için, uygun anaç ve çeşit/anaç kombinasyonlarının seçilmesi büyük önem taşımaktadır.

Eriş ve ark. (1989)'nın bildirdiğine göre; fidan üretiminde randıman ve kaliteyi arttırmak için, kalem/anaç arasındaki kallus bağlantısının çok iyi olması gerekmektedir. Baydar ve Ece (2005) yaptıkları çalışmada, fidan randımanı ve kalitesinin kullanılan çeşit/anaç kombinasyonlarına göre değiştiğini belirtmişlerdir.

Karauz ve Çelik (2007), Razakı ve Trakya ilkeren üzüm çeşitlerinden değişik dönemlerde alınan aşı kalemlerinde, gözlerin uyanması ve kallus gelişimi üzerine soğukta muhafazanın etkilerini araştırdıkları çalışmalarında, soğuk hava muamelesinden geçirilen aşı kalemleri ile ürettikleri aşılı fidanların, kontrole kıyasla daha yüksek olduğunu bildirmişlerdir.

Bhujbal (1993), Dog Ridge, 1103P, 41B, SO4 ve Salt Creek anaçları ve Thompson Seedless çeşidini kullandıkları çalışmasında, en iyi köklenme ve aşı tutum oranını 1103P anacının verdiğini belirlemiştir.

Kahraman ve ark. (2012) yapmış oldukları çalışmada, 1103 Paulsen anacı ile Cardinal ve Alphonse Lavallèe üzüm çeşitlerinin aşı tutma ve kaynaşma oranlarının yüksek olduklarını bildirmişlerdir. Ancak Alphonse Lavallee/1103 P kombinasyonunun fidan randımanının düşük olduğu kaydedilmiştir. 1103 Paulsen anacı ile Uslu ve Yalova İncisi üzüm çeşitlerinin kombinasyonlarında ise sürgün boyunun iyi olduğunu bildirmişlerdir.

Dardeniz ve Şahin (2005) 5BB, 140Ru, 41B ve 1103P anaçları üzerine Uslu ve Yalova İncisi üzüm çeşitlerini aşılamışlardır. En yüksek aşı odası randımanları 140Ru, $1103 \mathrm{P}$ ve 5BB anaçları üzerine aşılı Uslu çeşidinden sırasıyla \%98,75, $\% 96,27$ ve $\% 92,63$ olarak elde edilirken, en yüksek fidan randımanı $41 B$ ve $5 B B$ üzerine aşılı Uslu çeşidinde sırasıyla $\% 44,61$ ve $\% 37,47$ olarak belirlenmiştir.

Ağaoğlu ve Çelik (1982) çalışmalarında, Hafızali, Hamburg Misketi ve Hasandede üzüm çeşitlerini Kober 5BB ve 99R anaçları üzerine aşılamış ve toplam fidan randımanının \%20-60 arasında değiştiğini tespit etmişlerdir.

Günen (2008), Syrah ve Cabernet Sauvignon çeşitlerinin beş farklı anaçla olan kombinasyonlarını açık ve örtü altında kıyasladıkları çalışmada, ortamın istatistiksel olarak önemli bir etkiye sahip olmadığını tespit etmiştir. En yüksek başarıyı Syrah çeşidinde birinci yıl \%91.67, ikinci yıl \%60.42 ile 1103 Paulsen; Cabernet Sauvignon çeşidinde ise birinci yıl \%90.08, ikinci yıl \%63.33 ile yine 1103 Paulsen anacında elde ettiklerini bildirmiştir.

Cangi ve ark. (2000), aşıda başarı oranı (\%) ve kallus gelişim düzeyi (0-4) bakımından, su ve talaş ortamlarını, ponza ortamına kıyasla daha başarılı bulmuşlardır. Su ortamının dikilebilecek nitelikte aşılı çelik sayısı yönünden en yüksek, ponza ortamının ise en düşük değerleri sağladığını bildirmişlerdir. Kelen (1994), su ve talaş ortamında kaynaştırmaya alınan aşılı çeliklerde aşıda başarı yönünden ortamlar arasında önemli bir farklılık bulunmadığını, kallus gelişim düzeyi bakımından ise talaş ortamının daha iyi sonuç verdiğini bildirmektedir.

$\mathrm{Bu}$ çalışmada; ülkemizde yaygın olarak kullanılmakta olan 1103 P Amerikan asma anacı üzerine aşılı, ticari değeri yüksek olan sofralık çeşitlerden olan Cardinal, Ata Sarısı, Uslu, Trakya Illkeren, Alphonse Lavallèe, Hamburg Misketi, 
Çavuş ve Yalova İncisi üzüm çeşitlerinin açık köklü fidan randımanının saptanması amaçlanmıştır.

\section{Materyal ve Yöntem}

Çalışma, Tokat Merkez ilçede bulunan Kazova Vasfi Diren Tarım İşletmesi'nin bağ fidanı üretim tesisinde 2017 yılında yürütülmüştür. Denemede bitkisel materyal olarak ülkemizin birçok yöresi için önerilen 1103 P Amerikan Asma Anacı ile Cardinal, Ata Sarısı, Uslu, Trakya IIlkeren, Alphonse Lavallèe, Hamburg Misketi, Çavuş ve Yalova İncisi üzüm çeşitleri kullanılmıştır.
Roux (1988)'un bildirdiği gibi bir yıllık dalların iyi odunlaşmış orta kısımlarından alınan çubuklar tek gözlü kalemler halinde kesilerek, kalınlıklarına göre sınıflandırılmış (7-8 mm, 9-10 mm ve 11-12 $\mathrm{mm}$ kalınlıklarda)'tır. Daha sonra Kurşuni küf (Botrytis cinerea)'e karşı $500 \mathrm{~g} / \mathrm{l}$ Fenhexamid etken maddeli ilaçı su ile nemlendirilmiş perlitle harmanlanarak polietilen plastik torbalar içerisinde aşı dönemine kadar; $+4^{\circ} \mathrm{C}$ sıcaklıkta soğuk hava deposunda muhafaza edilmişlerdir (Şekil 1).

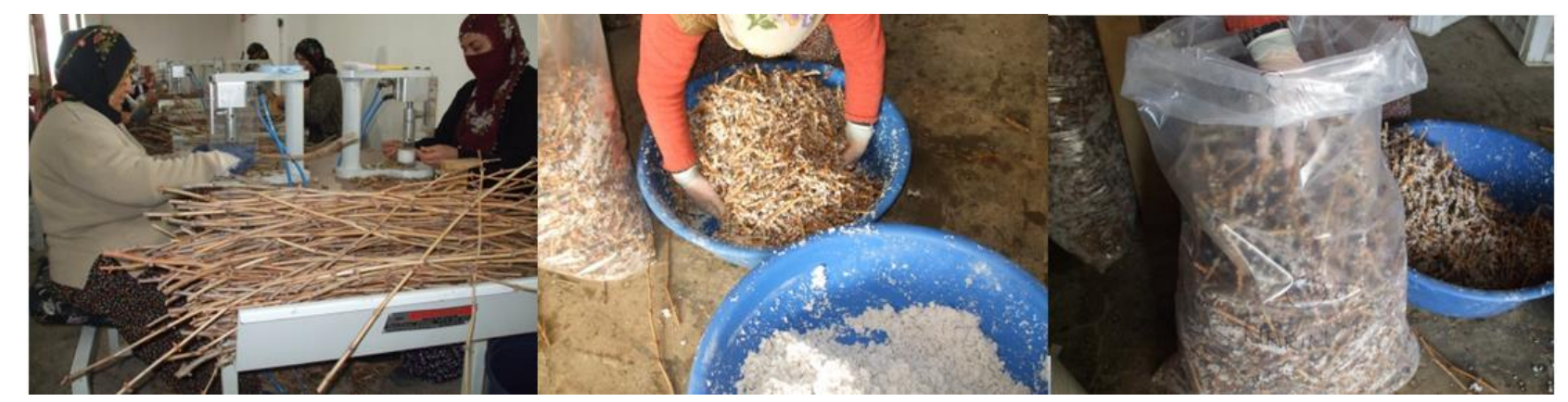

Şekil 1. Soğuk hava deposuna kaldırılmak üzere hazırlanmış aşı kalemleri

Figure 1. Prepared scion cuttings for storage in the cold storage room

Anaçlara ait çelikler, aşıdan kısa bir süre önce altta bir göz bulunmak üzere $30 \mathrm{~cm}$ boyunda kesilerek kalınlıklarına göre sınıflandırımış (7-8 mm, 9-10 mm ve 11-12 mm kalınlıklarda)'tır. Şekil 2'de görüldüğü gibi en alttaki göz hariç diğer gözler köreltilmiş ve 100'erlik demetler haline bağlanarak aseptik çuvallara konularak soğuk hava deposuna kaldırılmıştır.

Aşılama öncesi soğuk hava deposundan çıkarılan kalemler (üzerindeki perlitten yıkanarak arındırılmış) ve anaçlar üç gün dışarıda (kapalı bir alanda) bekletilmiştir. Anaçlar iki gün (48 saat), çeşitlere ait kalemler ise bir gün (24 saat) suyla dolu varil ve havuzlar içerisinde bekletilmiştir (Şekil 3). Bu işlemin tamamlanmasına son 6 saat kala sadece kalemlerin bekletme suyuna mantari hastalıkların gelişmesini önlemek amacıyla \% 50 Benomyl etkili ilaçlarla dezenfekte edilmiştir.

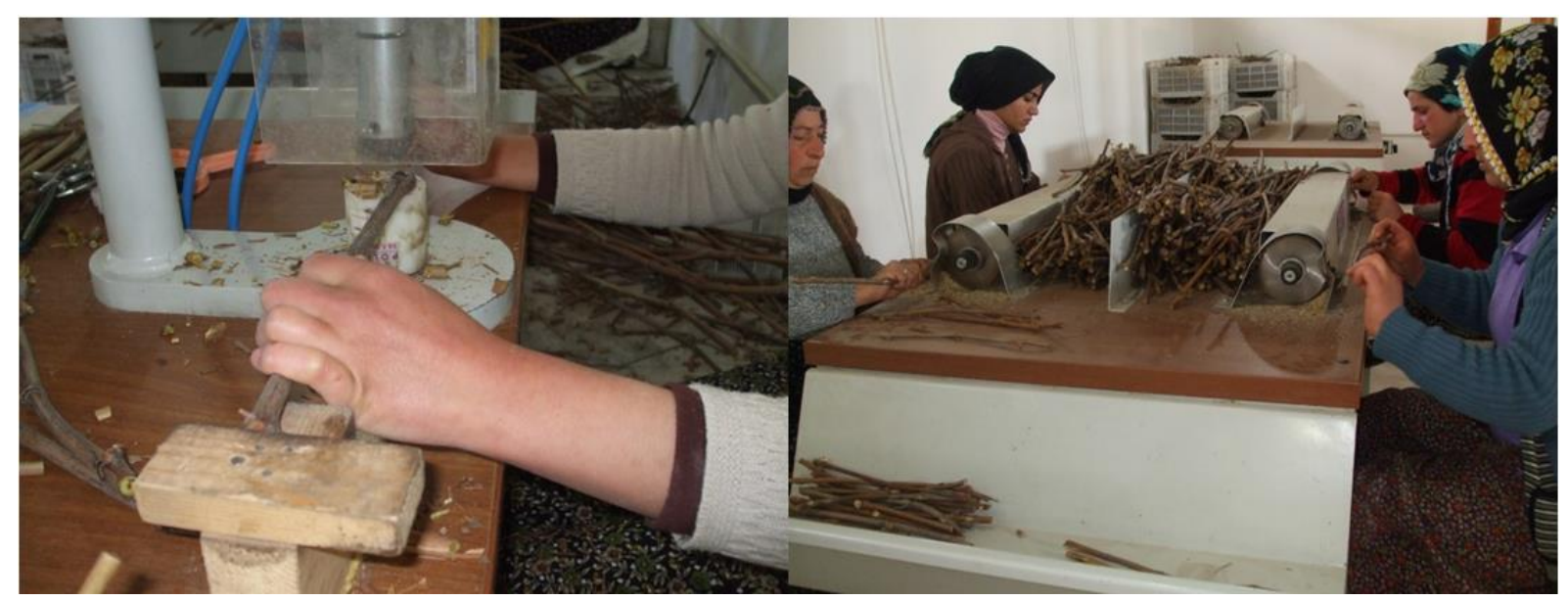

Şekil 2. Anaçlara uygulanan işlemler

Figure 2. Processes applied to rootstock 


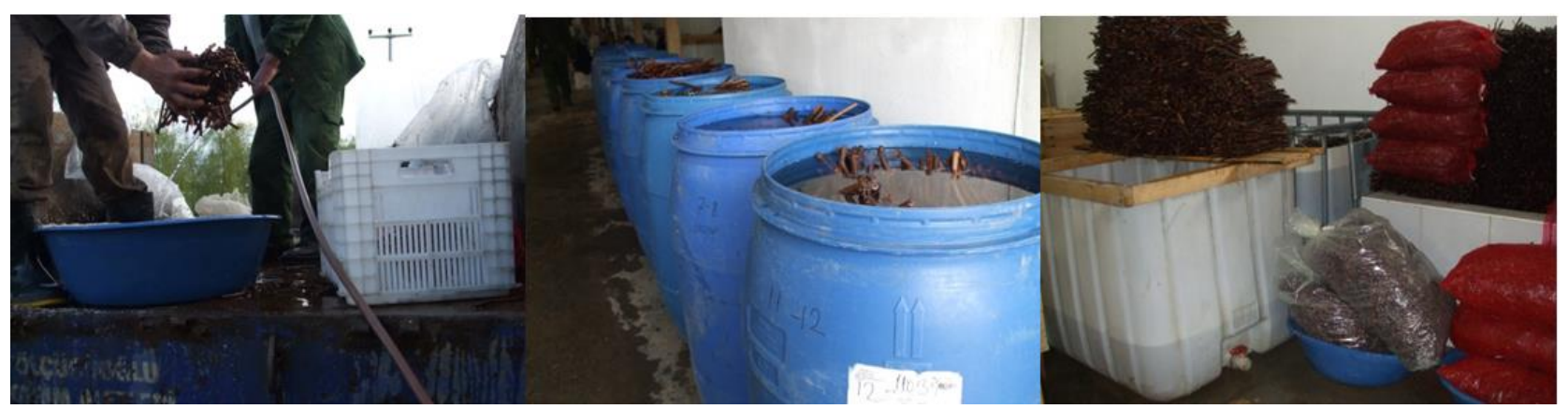

Şekil 3. Aşı Kalemi ve anaçlara uygulanan aşı öncesi ön hazırlıklar

Figure 3. Pre-preparations applied before the grafted to the scion cuttings and rootstocks

Denemede masabaşı omega aşısı ile 1103 Paulsen Amerikan asma anacı üzerine Cardinal, Ata Sarısı, Uslu, Trakya illkeren, Alphonse Lavallèe, Hamburg Misketi, Çavuş ve Yalova İncisi olmak üzere sekiz sofralık çeşit 3 tekerrürlü olarak ve her tekerrürde 500 adet aşılı çelik olmak üzere toplam 12.000 adet aşılı çelik hazırlanmıştır. Aşılama işleminden hemen sonra aşılı çeliklerin üstten yaklaşık 6 cm'lik kısımlarına \%1-5 arasında balmumu, vazelin, reçine, bitumen, zift, mineral yağ gibi maddelerin yanısıra, etkili oranda fungusit ve oksin katılarak hazırlanmış, $82^{\circ} \mathrm{C}^{\prime}$ de eritilen ticari parafin kullanılarak parafinleme işlemi gerçekleştirilmiştir. Parafinleme işleminden hemen sonra aşılı çelikler çimlendirme ortamı olarak ince kavak talaşı içerisinde Richter sandıklarına dizilmiştir (Şekil 4).

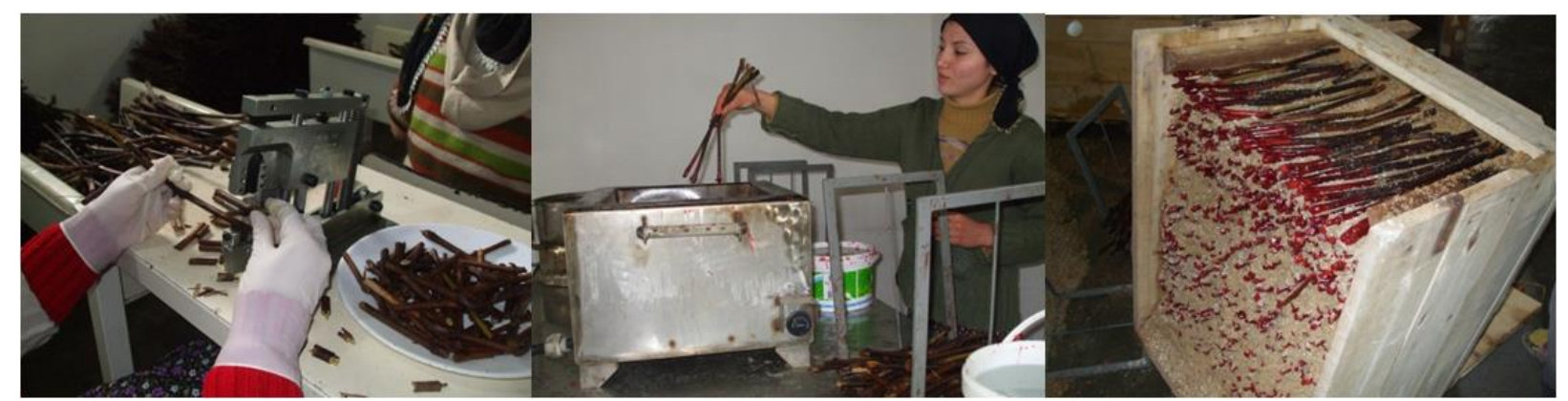

Şekil 4. Omega aşının yapılışı, parafinleme ve Richter sandıklarına aşılı çeliklerin dizilişi

Figure 4. Making of omega grafting, waxing and arrange of grafted cuttings in Richter crates

Richter sandıklarına dizilen aşılı çelikler kaynaştırma odasında kaynaştırmaya alınmıştır. Kaynaştırma odası koşulları: 3 gün $28-29^{\circ} \mathrm{C}, 15$ gün $25-26^{\circ} \mathrm{C}$ ve 3 gün $22-24^{\circ} \mathrm{C}$; nem oranı $\% 90$ 95; 6-12 saatte bir havalandırma (Çelik, 1982; Akman ve Ilgın, 1991) olacak şekilde düzenlenmiştir. 21 gün Richter sandıkları içerisinde kaynaştırma odasında kalan aşılı çelikler dışarıya çıkarılarak 2 gün kapalı bir ortamda bekletilmiştir. Sandıklar açılarak, temizlenmiş ve çepeçevre kallus gelişimi sağlanmış aşılı çeliklere ikinci parafinleme yapılmıştır. Daha sonra su dolu havuzlarda 12 saat (bir gece) bekletilen aşılı çelikler, sudan çıkarılarak 2 saat dinlendirilmiştir (Şekil 5).

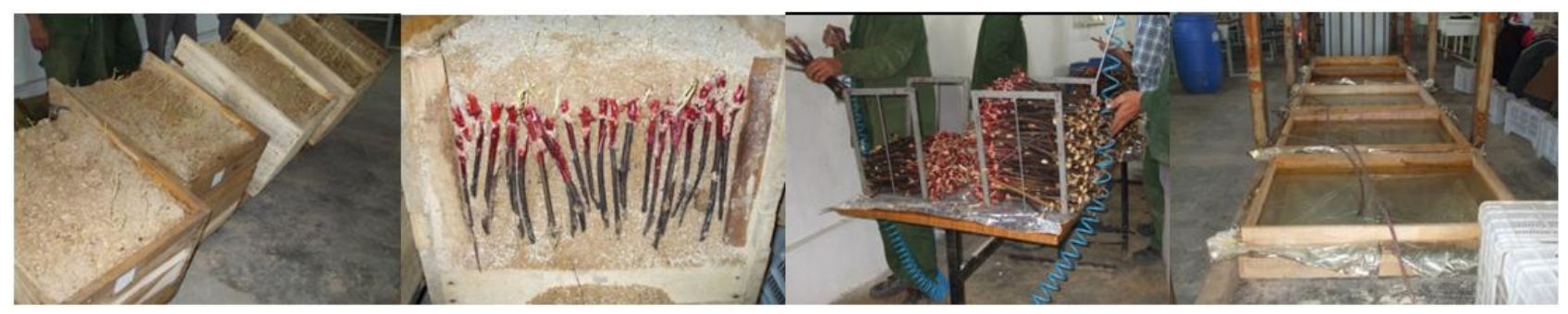

Şekil 5. Kaynaştırma odası sonrası yapılan işlemler

Figure 5. Processes applied after callusing room 
Araziye almadan hemen önce aşılı çeliklere 2000 ppm IBA (indole-3 butyric acid) uygulanmış ve daha önceden plastik malç serilerek hazırlanmış masuralara aşılı çeliklerin dikimi SAxSÜ $=20 \mathrm{~cm} \times 10 \mathrm{~cm}$ olacak şekilde çift sıralı olarak gerçekleştirilmiştir (Şekil 6).

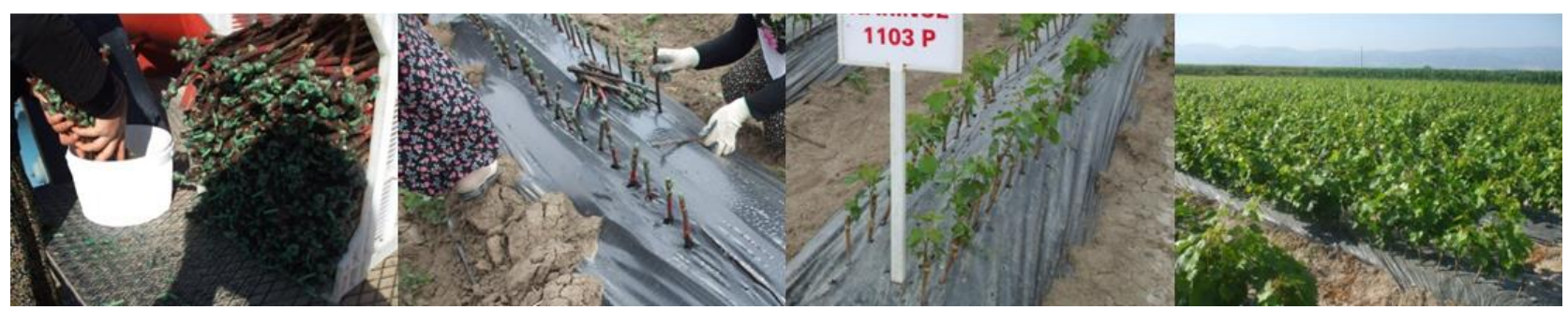

Şekil 6. Aşılı çeliklerin araziye dikimi

Figure 6. Planting of grafted cuttings

Yaprak dökümünü takiben 20 Kasım'da fidanlar araziden sökülmüştür. Satışı yapılabilecek 1. ve 2 . boy fidanlar sayılarak sekiz sofralık üzüm çeşidinin 1103 Paulsen Amerikan asma anacı ile olan fidan randımanı \% olarak belirlenmiştir.

$$
\mathrm{FR}=\left[\frac{S S F M}{A C ̧ M}\right] x 100
$$

Eşitlikte; FR= Fidan Randımanı (\%), SSFM= Satışa Sunulan Fidan Miktarı (adet), AÇM= Aşılı Çelik Miktarı (adet)'dır.

\section{Istatistiksel analiz}

Deneme tesadüf parselleri deneme desenine göre 3 tekerrürlü olarak yürütülmüştür. Veriler varyans analizi ile analiz edildikten sonra, ortalamalar arasındaki fark \% 1 düzeyinde Tukey çoklu karşılaştırma testi ile incelenmiştir. Analizde JMP paket programı kullanılmıştır. İstatistiksel farklılık, verilerin sağ tarafında küçük harfle gösterilmiştir.

\section{Standart Hata (SH)}

Çalışmada elde edilen tüm verilerin kendi içinde karşılaştırılabilmesi için standart hata hesaplaması yapılmıştır.

\section{Bulgular ve Tartışma}

Çalışmamızda elde edilen veriler Çizelge 1'de görüldüğü gibidir.

Çizelge 1. Çeşitlerin 1103 Paulsen Amerikan asma anacı ile olan fidan randımanı Table 1. Sapling yield of varieties with 1103 Paulsen American vine rootstock

\begin{tabular}{|c|c|c|c|c|c|c|}
\hline $\begin{array}{l}\text { Çeşitler } \\
\text { Varieties }\end{array}$ & $\begin{array}{c}\text { Anaç } \\
\text { rootstock }\end{array}$ & $\begin{array}{c}\text { AÇM } \\
\text { (adet) } \\
A G C \\
\text { (amount) }\end{array}$ & $\begin{array}{c}\text { SSFM } \\
\text { (adet) } \\
\text { ASOS } \\
\text { (amount) }\end{array}$ & $\begin{array}{l}\text { KGGAÇM } \\
\text { (adet) } \\
\text { AGCWCG } \\
\text { (amount) }\end{array}$ & $\begin{array}{l}\text { FR } \\
(\%) \\
R S Y \\
(\%)\end{array}$ & $\begin{array}{l}\text { KGGAÇO } \\
(\%) \\
R G C W C G \\
(\%)\end{array}$ \\
\hline Cardinal & & 500 & $429.67 \pm 4.63 \mathrm{c}$ & $70.33 \pm 4.63 \mathrm{~d}$ & $85.93 \pm 0.93 c$ & $14.07 \pm 0.93 \mathrm{~d}$ \\
\hline Ata Sarısı & & 500 & $451.67 \pm 4.06 \mathrm{~b}$ & $48.33 \pm 4.06 \mathrm{e}$ & $90.33 \pm 0.81 b$ & $9.67 \pm 0.81 \mathrm{e}$ \\
\hline Uslu & & 500 & $374.33 \pm 2.60 \mathrm{e}$ & $125.67 \pm 2.60 \mathrm{~b}$ & $74.87 \pm 0.51 \mathrm{e}$ & $25.13 \pm 0.51 b$ \\
\hline Trakya Illkeren & 1103 & 500 & $492.67 \pm 1.76 \mathrm{a}$ & $7.33 \pm 1.76 \mathrm{f}$ & $98.53 \pm 0.35 \mathrm{a}$ & $1.47 \pm 0.35 \mathrm{f}$ \\
\hline Alphonse Lavallèe & Paulsen & 500 & $368.00 \pm 4.04 \mathrm{e}$ & $132.00 \pm 4.04 \mathrm{~b}$ & $73.60 \pm 0.81 \mathrm{e}$ & $26.40 \pm 0.81 b$ \\
\hline Hamburg Misketi & & 500 & $337.67 \pm 3.28 f$ & $162.33 \pm 3.28 \mathrm{a}$ & $67.53 \pm 0.66 f$ & $32.47 \pm 0.66 \mathrm{a}$ \\
\hline Çavuş & & 500 & $410.67 \pm 1.76 \mathrm{~d}$ & $89.33 \pm 1.76 \mathrm{c}$ & $82.13 \pm 0.35 \mathrm{~d}$ & $17.87 \pm 0.35 c$ \\
\hline Yalova İncisi & & 500 & $422.33 \pm 4.91 \mathrm{~cd}$ & $77.67 \pm 4.91 \mathrm{~cd}$ & $84.47 \pm 0.98 \mathrm{~cd}$ & $15.53 \pm 0.98 \mathrm{~cd}$ \\
\hline
\end{tabular}

Ortalama $\pm \mathrm{SH}$. Aynı sütunda farklı harfle gösterilen ortalamalar arasında Tukey Çoklu Karşılaştırma Testi'ne göre $\mathrm{P}<0,01$ düzeyinde farkııık vardır. AÇM: Aşılı Çelik Miktarı, SSFM: Satışa Sunulan Fidanı Miktarı, KGGAÇM: Kallus Gelişimi Görülmeyen Aşıı Çelik Miktarı, FR: Fidan Randımanı, KGGAÇO: Kallus Gelişimi Görülmeyen Aşılı Çelik Oranı Mean $\pm S D$. There are differences between the means indicated by different letters in the same column according to the Tukey Multiple Comparison Test (P<0,01). AGC: Amount of Grafted Cuttings, ASOS: Amount of Saplings Offered for Sale, AGCWCG: Amount of Grafted Cuttings Without Callus Growth, RSY: Ratio of Saplings Yield, RGCWCG: Ratio of Grafted Cuttings Without Callus Growth 
Satışa sunulan açık köklü açık asma fidanı miktarı, en fazla 492.67 adet ile Trakya İlkeren/1103 Paulsen kombinasyonunda olurken, en az 337.67 adet ile Hamburg Misketi/1103 Paulsen kombinasyonunda olmuştur. Satışa sunulan aşılı asma fidanı miktarı bakımından çeşitler arasında \%1 düzeyinde istatistiksel bir fark tespit edilmiştir. Alphonse Lavallèe ile Uslu çeşitleri arasında ise istatistiksel bir fark belirlenememiştir. Fidan randımanı ise, en fazla \% 98.53 ile Trakya Ilkeren/1103 Paulsen kombinasyonunda görülürken, en az \% 67.53 ile Hamburg Misketi/1103 Paulsen kombinasyonunda saptanmıştır.

Kallus gelişimi görülmeyen aşılı çelik miktarı, en çok 162.33 adet ile Hamburg Misketi /1103 Paulsen kombinasyonunda, en az 7.33 adet ile Trakya ilkeren/1103 Paulsen kombinasyonunda belirlenmiştir. Kallus gelişimi görülmeyen aşılı çelik miktarı bakımından çeşitler arasında \% 1 düzeyinde istatistiksel bir fark tespit edilmiştir. Alphonse Lavallèe ile Uslu çeşitleri arasında ise istatistiksel bir fark belirlenememiştir. Kallus gelişimi görülmeyen aşılı çelik oranı ise, en çok \% 32.47 ile Hamburg Misketi/1103 Paulsen kombinasyonunda olurken, en az \% 1.47 ile Trakya Ilkeren/1103 Paulsen kombinasyonunda tespit edilmiştir.

Isparta koşullarında farklı çeşit/anaç kombinasyonlarının karşılaştırıldığı bir çalışmada, aşılı asma fidanları omega masa başı aşısıyla üretilmiştir. Alphonse Lavallèe/1103 Paulsen kombinasyonun aşı tutma oranın \% 98.32 olarak belirlemişlerdir (Baydar ve Ece, 2005). Çalışmamızda elde ettiğimiz Alphonse Lavallèe/1103 Paulsen kombinasyonun aşı tutma oranı, bu çalışma sonuçlarının gerisinde kalmıştır.

1103 Paulsen, 5BB ve S04 köklü anaçları üzerine Alphonse Lavallèe ve Cardinal üzüm çeşitlerini aşılayan Çelik ve Gider (1991), aşı başarısının çeşit/anaç kombinasyonuna göre değiştiğini ve en yüksek başarıyı \% 98.08 ile Cardinal/1103P kombinasyonundan elde ettiklerini belirtmişlerdir. Çalışmada elde edilen sonuçlar paralellik göstermektedir.
Kavak (2006) Mycorrhiza ve humik asit uygulamalarının fidan randımanı üzerine etkilerini araştırdıkları çalışmada, kontrol grubu aşılı çeliklerde en yüksek aşı başarısını \% 70.00 ile Yalova İncisi/1103P kombinasyonunda elde etmiştir. Çalışmamızda bu araştırıcının elde ettiği aşı başarısının üzerinde bir başarı oranı elde edilmiştir.

İş̧i ve Altındişli (2006) köklü Amerikan asma anaçlarına yerinde kakma aşı yaptıkları çalışmalarında, Trakya İlkeren çeşidinin aşı tutma yüzdesini $41 \mathrm{~B}$ anacı ile olan interaksiyonunda \%100, $110 \mathrm{R}$ anacında \% 81 olarak saptamışlardır. Yine aynı çalışmada Alphonse Lavallèe çeşidinin aşı tutma yüzdesini $41 \mathrm{~B}$ anacı ile olan interaksiyonunda \% 96, $110 \mathrm{R}$ anacında \% 87 olarak tespit etmişlerdir. Oysa, çalışmamızda elde ettiğimiz Trakya ilkeren/1103 Paulsen kombinasyonun aşı tutma oranı \% 98.53, Alphonse Lavallèe/1103 Paulsen kombinasyonun aşı tutma oranı \% 73.60 olarak belirlenmiştir.

Alço ve ark. (2015) farklı çeşit/anaç kombinasyonlarını araştırdıkları çalışmalarında, 5 BB anacına aşılanan Cardinal, Merlot ve Cabernet Sauvignon üzüm çeşitlerinin aşı odası randımanlarını, 2012 yılında sırasıyla \% 99.50, 99.75 ve 99.50; 2013 yılında ise sırasıyla \% 74.25, 70.50 ve 86.75 olarak belirlemişlerdir. Aynı üzüm çeşitlerinin 110R anacı üzerine aşılanmasıyla aşı odası randımanlarını, 2012 yılında sırasıyla \% $96.50,98.75$ ve $98.75 ; 2013$ yılında ise sırasıyla \% $97.75,96.25$ ve 86.25 olarak saptamışlardır.

Çakır ve Yücel (2016) 1103 Paulsen anacı üzerine aşılı Narince ve Kalecik Karası üzüm çeşitlerinin aşı performansını belirledikleri çalışmalarında, kallus oluşumunu Narince çeşidinde \% 77, Kalecik Karası çeşidinde \% 60 olarak tespit etmişlerdir. 1103 Paulsen anacının diğer çeşitlerle olan aşı kombinasyonu incelediğimiz çalışmamızda ise birçoğunun bu çalışmada elde edilen sonuçlardan daha yüksek bir aşı performansı gösterdiği belirlenmiştir.

Günen ve Altındişli (2017), Cabernet Sauvignon çeşidinin üç farklı anaçla olan kombinasyonlarını açık ve örtü altında kıyasladıkları çalışmalarında, ortamın istatistiksel olarak önemli bir etkiye sahip 
olmadığını ve en yüksek aşı başarısının birinci yıl \% 90.08, ikinci yı \% 63.33 ile 1103 Paulsen anacında elde ettiklerini bildirmişlerdir.

Yağcı ve Gökkaynak (2016) Sultani Çekirdeksiz üzüm çeşidinin farklı anaçlar üzerindeki fidan randımanını araştırdıkları çalışmalarında, $110 \mathrm{R}$, 140 Ruggeri, 1613 C, 5 BB ve Ramsey anaçlarını kullanmışlar ve toplam fidan randımanını sırasıyla $\% 51.5,40.4,50.3,57.3$ ve 50.2 olarak belirlemişlerdir.

\section{Sonuç}

Filoksera zararlısının ülkemiz bağ alanlarına girmesiyle yerli bağcılık yapılamaz hale gelmiştir. $\mathrm{Bu}$ nedenle filokseraya dayanıklı, ekolojik koşullara adaptasyonu iyi ve üretilecek olan üzüm çeşitleriyle iyi uyuşma gösteren Amerikan asma anaçları kullanarak bağ tesis etmek zorunlu hale gelmiştir. Ülkemizde yaygın olarak kullanılmakta olan 1103 P Amerikan asma anacı üzerine sekiz sofralık üzüm çeşidinin masa başı omega aşı yöntemiyle aşılanması sonucu gerçekleştirdiğimiz çalışmada, 1103 Paulsen anacıyla en yüksek aşı tutma oranına sahip çeşit Trakya ilıkeren (\% 98.53) olurken, en düşük performans Hamburg Misketi (\% 67.53) çeşidinde belirlenmiştir. Aşılı asma fidanlarında ortaya çıkabilecek gecikmiş uyuşmazlıklara karşı bu çalışmada elde edilen veriler ön bilgi açısından önemlidir. Ancak fidanlar bağ yerine dikildikten sonra da gerekli kontroller devam ettirilmelidir. Üreticilere yetiştiriciliği yapılacak çeşitlerle ilgili önerilerde bulunurken bahsedilen özelliklerin dikkate alınması, bağcılık açısından başarıya ulaşmada yararlı olacaktır.

\section{Kaynaklar}

Ağaoğlu, Y.S., \& Çelik, H. (1982). Effect of grafting machines on success of grafted vine production. U.Ü. Zir. Fak. Dergisi, 1, 25-32.

Akman, İ., \& Ilgın, C. (1991). Tüplü asma fidanı üretiminde başarıyı etkileyen faktörler. Türkiye 1. Fidancılık Sempozyumu, 153- 159, Ankara.

Alço, T., Dardeniz, A., Sağlam, M., Özer, C., \& Açıkbaş, B. (2015). Aşılı asma fidanı üretiminde farklı çeşit/anaç kombinasyonlarının aşı odası randımanı ile kallus gelişim düzeyi üzerine etkileri. Selçuk Üniversitesi, Selçuk Tarım ve Gıda Bilimleri Dergisi-A 27 (Türkiye 8.
Bağcılık ve Teknolojileri Sempozyumu Özel Sayısı), 816.

Baydar, N.G., \& Ece, M. (2005). Isparta koşullarında aşılı asma fidanı üretiminde farklı çeşit/anaç kombinasyonlarının karşılaştırılması. Süleyman Demirel Üniversitesi, Fen Bilimleri Enstitüsü Dergisi, 9(3).

Bhujbal, B. G. (1993). Performance of five grape rootstocks for rooting and grafting. Maharashtra Journal of Horticulture, 7(1), 7-9.

Cangi, R., Balta, F., \& Doğan, A. (2000). Aşılı asma fidanı üretiminde kullanılan kaynaştırma ortamının fidan randıman ve kalitesi üzerine etkilerinin anatomik ve histolojik olarak incelenmesi. Turk. J. Agric. For, 24(3), 393-398.

Çakır, A., \& Yücel, B. (2016). Narince ve Kalecik Karası üzüm çeşitlerinin 1103 Paulsen Amerikan asma anacı ile aşı performanslarının belirlenmesi. Türk Tarım ve Doğa Bilimleri Dergisi 3(4), 311-317.

Çelik, H. (1982). Kalecik karası/41 B aşı kombinasyonu için sera koşullarında yapılan aşılı-köklü fidan üretiminde değişik köklenme ortamları ve NAA uygulamalarının etkileri. (Basılmamış Doçentlik tezi). Ankara Üniversitesi, $73 \mathrm{~s}$.

Çelik, H., Ağaoğlu, Y. S., Fidan, Y., Marasalı, B., \& Söylemezoğlu, G. (1998). Genel Bağcılık. Sun Fidan A. Ş. Mesleki Kitaplar Serisi: 1, Ankara, $253 \mathrm{~s}$.

Çelik, S. (2007). Bağcılık (Ampeloloji). Namık Kemal Üniversitesi, Ziraat Fakültesi, Bahçe Bitkileri Bölümü. Cilt I. Genişletilmiş 2. Baskı, $428 \mathrm{~s}$. Tekirdağ.

Çelik, S., \& Gider, S. (1991). Bağ kurmak amacıyla dikilen köklü anaçların aynı yıl içinde aşılanması. T.C. Tarım ve Köyişleri Bakanlığı Türkiye 1. Fidancılık Sempozyumu, 113-121.

Dardeniz, A., \& Şahin, A. O. (2005). Aşılı asma fidanı üretiminde farklı çeşit ve anaç kombinasyonlarının vejetatif gelişme ve fidan randımanı üzerine etkileri. Bahçe Dergisi, 34(2), 1-9.

Eriş, A., Soylu, A., \& Türkben, C. (1989). Aşılı köklü asma fidanı üretiminde bazı uygulamaların aşı yerinde kallus oluşumu ve köklenme üzerine etkileri. Bahçe, 18(1-2), 29-34.

Günen, E. (2008). Bazı şaraplık üzüm çeşitlerinin aşılı köklü asma fidanlarının üretiminde anaç kalem ilişkileri ve üretim şekillerinin fidan randımanı ile kalitesine etkileri üzerinde araştırmalar. (Doktora Tezi). Ege Üniversitesi, Fen Bilimleri Enstitüsü, $217 \mathrm{~s}$.

Günen, E., \& Altındişli, A. (2017). Cabernet Sauvignon üzüm çeşidinin bazı Amerikan asma anaçları ile aşı kombinasyonlarının örtü altı ve açıkta yetiştiricilik koşullarında tüplü fidan performanslarının değerlendirilmesi. Ege Üniv. Ziraat Fak. Derg., 54(1), 91-99.

İlter, E., Kısmalı, İ., Atilla, A., \& Uzun i. (1984). Asma fidanı sorunu ve çözümü için öneriler. Türkiye II. Bağcılık ve Şarapçılık Sempozyumu. T.C. Tarım ve Köyişleri Bakanlığı Bağcılık Araştırma Enstitüsü Müdürlüğü, 23-31.

İşçi, B., \& Altındişli, A. (2006). Bazı üzüm çeşitlerinin 41 B ve 110 R Amerikan asma anaçları ile aşı tutma yüzdesi üzerine araştırmalar. Ege Üniv. Ziraat Fak. Derg., 43(2), 13-25. 
Janick, J. (1986). Horticultural Science. Macmillan, 4th. Ed., W.H. Freeman and Company, New York, 39, 346-746.

Kahraman, K.A., Dardeniz, A., \& Atak, A. (2012). Asma fidancılığında farklı sofralık çeşit/anaç kombinasyonlarının genel özelliklerinin incelenmesi. IV. Ulusal Üzümsü Meyveler Sempozyumu. 3-5 Ekim, Antalya.

Karauz, A., \& Çelik, S. (2007). "Değişik dönemlerde alınan asma aşı kalemlerinde gözlerin uyanması ve kallus oluşumu üzerine soğukta muhafazanın etkileri" projesinin sonuç raporu, 17 s., Bağcılık Araştırma Enstitüsü Müdürlüğü, Tekirdağ.

Kavak, O. (2006). Aşılı köklü, tüplü asma fidanı üretiminde fidan kalite özelliklerine mycorrhiza ve humik asit uygulamalarının etkileri. (Yüksek Lisans Tezi). Selçuk Üniversitesi, Fen Bilimleri Enstitüsü, $52 \mathrm{~s}$.

Kelen, M. (1994). Bazı uygulamaların aşılı-köklü asma fidanı üretiminde fidan randımanı ve kalitesi üzerine etkileri ile aşı kaynaşmasının anatomik ve histolojik olarak incelenmesi üzerine araştırmalar. (Doktora Tezi). Y.Y.Ü. Fen Bil. Ens. $131 \mathrm{~s}$.
Kısmalı, İ. (1978). Yuvarlak çekirdeksiz üzüm çeşidi ve farklı Amerikan asma anaçları ile yapılan aşılı köklü asma fidanı üretimi üzerinde araştırmalar. (Basılmamış Doçentlik Tezi). $102 \mathrm{~s}$.

Roux, Le D.J. (1988). The collection and storage of vineyard grafting material. VORI leaflet, 209. Stellenbosch, South Africa, 2 p.

Söylemezoğlu, G., Dumanoğlu, H., Çelik, H., Kunter, B., Atıcı, A., \& Tahmaz, H. (2010). Türkiye'de asma ve meyve fidanı üretimi ve kullanımı. Ziraat Mühendisliği VII. Teknik Kongresi, 891-907, 11-15 Ocak, Ankara.

Winkler, A. J., Cook, J. A., Kliewer, W. M., \& Lider, L. A. (1974). General Viticulture. University of California Press., Berkeley and Los Angeles, 633 p.

Yağcı, A., \& Gökkaynak, A. G. (2016). Sultani Çekirdeksiz üzüm çeşidinin fidan randımanı ve kalitesi üzerine anaç ve gölgeleme oranının etkisi. Ege Üniv. Ziraat Fak. Derg., 53 (1), 109-116.

Yayla, F. (2008). "Milli koleksiyon bağındaki üzüm çeşitlerinin şaraplık özelliklerinin araştırılması" projesi ara sonuç raporu, 4 s., Bağcılık Araştırma Enstitüsü Müdürlüğü, Tekirdağ. 